\title{
Efforts to Improve Indonesian Learning Results in Command Sentence through The Discovery Learning Model Assisted with Video Applications
}

\section{Tenti Budiastuti}

SD Negeri Sindangheula 01

tentibudiastuti2@gmail.com

\section{Article History}

accepted 01/11/2020

\begin{abstract}
The purpose of this study was to improve the learning outcomes of students in the Indonesian language muple in grade II elementary schools through the discovery learning model assisted by video applications. Classroom Action Research (CAR) was conducted in three cycles with each cycle consisting of two meetings. Where each cycle begins with planning, implementing, observing, and reflecting. Each first time, a pre-test and a post-test were conducted to determine the students' progress. In the first cycle, the students who completed the post test were $58 \%$. In the second cycle, the students who completed the post test were $75 \%$. In the third cycle, the students who completed the post test were 92\%. These results indicate that the Discovery Learning learning model can improve the results of students, especially the class II class II SD Negeri Sindangheula 01.
\end{abstract}

Keywords: learning outcomes, Discovery Learning, Indonesian

\section{Abstrak}

Tujuan dari penelitian ini adalah untuk meningkatkan hasil belajar peserta didik pada mupel bahasa indonesia di sekolah dasar kelas II melalui model pembelajaran discovery learning berbantuan aplikasi video .Penelitian Tindakan Kelas yang dilakukan(PTK) dilakukan sebanyak tiga siklus dengan setiap siklusnya terdiri dari dua pertemuan. Dimana setiap siklusnya dimulai dengan perencanaan, pelaksanaan, observasi, dan refleksi. Setiap pertemuna dilakukan pre test dan post tes untuk mengetahui perkembangan peserta didik.Pada siklus I peserta didik yang tuntas setelah melaksanakan post test adalah $58 \%$. Pada siklus II peserta didik yang tuntas setelah melaksanakan post test adalah $75 \%$ Pada siklus III peserta didik yang tuntas setelah melaksanakan post test sebesar $92 \%$. Hasil iini menunjukkan bahwa model pembelajaran Discovery Learning dapat meningkatkan hasil peserta didik khususnya mupel bahasa indonesia kelas II SD Negeri Sindangheula 01.

Kata Kunci : hasil belajar,Discovery Learning,bahasa indonesia,

Social, Humanities, and Education Studies (SHEs): Conference Series https://jurnal.uns.ac.id/shes

p-ISSN 2620-9284 e-ISSN 2620-9292 


\section{PENDAHULUAN}

Pendidikan memiliki peranan penting dalam perkembangan suatu bangsa. Pendidikan dapat menciptakan sumber daya manusia yang berkualitas (Anugraheni, 2017: 2016). Proses pendidikan dipengaruhi oleh beberapa faktor, diantaranya (1) input peserta didik; (2) sarana dan prasarana pendidikan; (3) bahan ajar; serta (4) sumber daya manusia (pendidiknya) yang dapat mendukung terciptanya suasana kondusif (Anugraheni, 2017: 247).

Undang-Undang Republik Indonesia Nomor 20 Tahun 2003 tentang sistem pendidikan nasional merumuskan tentang dasar, fungsi, dan tujuan pendidikan nasional. Pasal 2 Undang-Undang Negara Republik Indonesia Tahun 1945, bertujuan mengembangkan potensi peserta didik agar menjadi manusia yang beriman dan bertakwa kepada Tuhan Yang Maha Esa, berakhlak mulia, sehat, cakap, berilmu, kreatif, mandiri, dan menjadi warga negara yang demokratis, serta bertanggung jawab (Depdiknas, 2006: 28).

Berdasarkan hasil evaluasi dalam aktivitas belajar peserta didik pada pembelajaran tema 1 subtema 3 kelas II SDN Sindangheula 01 Tahun Pelajaran 2020/2021 pada muatan pelajaran Bahasa Indonesia kurang begitu memuaskan, Dari total peserta didk 12 anak, dengan KKM 75, ada 9 anak yang yang mendapat nilai dibawah KKM dan ada 3 anak yang mencapai nilai KKM.itu berarti ada 75\% peserta didik yang belum mencapai KKM dan hanya $25 \%$ peserta didik yang sudah mencapai KKM

Permasalahan di atas membutuhkan usaha pemecahan masalah agar peserta didik termotivasi dalam proses pembelajaran dan tujuan pembelajaran tercapai sehingga hasil belajar peserta didik meningkat. Maka untuk mengatasi permasalahan tersebut perlu adanya penggunaan media pembelajaran yang dapat menarik minat belajar peserta didik sehingga peserta didik terangsang dalam melakukan proses pembelajaran, sehingga hasil belajar peserta didik dapat meningkat. Rendahnya hasil belajar pada peserta didik kelas II disebabkan oleh dominasi guru masih tinggi, peran guru dalam proses belajar mengajar berperan sebagai fasilitator, guru masih banyak bergantung pada buku, guru masih dominan menggunakan ceramah dan mencatat, guru masih melaksanakan proses pembelajaransecara konvensional Hal tersebut sangat mungkin disebabkan karena guru kurang variatif dalam penggunaan metode pembelajaran yang melibatkan peseta didik secara langsung dalam pembelajaran tematik.

Berdasarkan dari latar belakang masalah tersebut, guru harus memprioritaskan membuat pembelajaran yang menyenangkan serta melibatkan peran aktif siswa. Perbaikan pembelajaran dilakukan dengan menggunakan model pembelajaran Discovery Learning dengan berbantuan aplikasi video. Tujuan pelaksanaan tindakan adalah untuk meningkatkan hasil belajar Bahasa Indonesia dalam pembelajaran tematik.Menurut Hosnan (2014:282), discovery learning adalah suatu model untuk mengembangkan cara belajar aktif dengan menemukan sendiri, menyelidiki sendiri, maka hasil yang diperoleh akan setia dan tahan lama dalam ingatan. Melalui belajar penemuan, siswa juga bisa belajar berpikir analisis dan mencoba memecahkan sendiri masalah yang dihadapi. Penemuan pembelajaran adalah metode yang mendorong anak untuk mencapai kesimpulan atas kegiatan dan penilaian mereka sendiri dan mendukung hidup (Kaptan \& Korkmaz dalam Balim, 2009). Seorang pembelajar bisa membangun pengetahuan dengan sendirinya yang berasal dari percobaan, pengalaman, atau penemuan yang dia rasakan (Joolingen, 1998).

Menurut Syah (2004:244) dalam mengaplikasikan Discovery Learning di kelas, ada beberapa prosedur yang harus dilaksanakan dalam kegiatan belajar mengajar secara umum sebagai berikut: 1) Stimulation (Stimulasi/Pemberian Rangsangan), 2) Problem Statement 3) Data Collection (Pengumpulan Data)4) Data Processing (Pengolahan Data), 5) Verification (Pembuktian), 6) Generalization ( Menarik Kesimpulan/Generalisasi). 


\section{METODE}

Penelitian ini adalah penelitian Tindakan kelas dengan menerapkan model Discovery Learning. Menurut Syah (2004:244) dalam mengaplikasikan Discovery Learning di kelas, ada beberapa prosedur yang harus dilaksanakan dalam kegiatan belajar mengajar diantaranya:1) Stimulation (Stimulasi/Pemberian Rangsangan), 2) Problem Statement (Pernyataan/Identifikasi Masalah), 3) Data Collection (Pengumpulan Data),4) Data Processing (Pengolahan Data), 5) Verification (Pembuktian),6) Generalization ( Menarik Kesimpulan/Generalisasi).

Analisis ini adalah analisis berupa deskriptif kualitatif dan kuantitatif.dimana dalam penelitian ini selain menyajikan data berupa data maupun angka peneliti juga menentukan bagaimana cara pengolahan hasil penelitian yakni dengan membuat analisis dan menerapkan model Discovery Learning.Penelitiandilaksanakan pada peserta didik kelas II SD Negeri Sindangheula 01 Tahun Pelajaran 2020/2021 selama tiga siklus secara luring dengan dua pertemuan setiap siklusnya.Siklus I dilaksanakan pada tanggal 22 dan 23 Oktober 2020.Siklus Ildilaksanakan pada tanggal 2 dan 3 Nopember 2020.Siklus III pada tanggal 13 dan 14 Nopember 2020.Teknik pengumpulan data yang dilakukan dengan observasi dan tes baik pre test maupun post test,Observasi berupa observasi keterlaksanaan model pembelajaran Discovery Learning,sikap peserta didik dan keterampilan.

\section{HASIL DAN PEMBAHASAN}

Pada siklus I pembelajaran dilaksanakan selama dua pertemuan.setiap pertemuan diadakan pretes dan pos test.Untuk mengetahui perkembangan peserta didik selama pembelajaran.Siklus I membahas materip tentang kalimat perintah berupa menemukan kalimat perintah dari sebuah teks percakapan.Pembelajaran dengan model Discovery Learning dilaksanakan dengan 6 langkah secara berurutan mulai dari Berikut ini adalah hasil belajar peserta didik pada siklus I yang dapat didilhat pada table berikut

Tabel 1. Hasil Peserta Didik Siklus I

\begin{tabular}{|c|c|c|c|c|c|c|c|c|}
\hline \multirow{3}{*}{ Siklus } & \multicolumn{4}{|c|}{ Pre test } & \multicolumn{4}{|c|}{ Pos test } \\
\hline & \multicolumn{2}{|c|}{ Pesdik tuntas } & \multicolumn{2}{|c|}{$\begin{array}{c}\text { Pesdik belum } \\
\text { tuntas }\end{array}$} & \multicolumn{2}{|c|}{ Pesdik tuntas } & \multicolumn{2}{|c|}{$\begin{array}{l}\text { Pesdik belum } \\
\text { tuntas }\end{array}$} \\
\hline & Jml & $\%$ & $\mathrm{Jml}$ & $\%$ & Jml & $\%$ & $\mathrm{Jml}$ & $\%$ \\
\hline Pertemuan 1 & 3 & $25 \%$ & 9 & $75 \%$ & 4 & $33 \%$ & 8 & 67 \\
\hline Pertemuan 2 & 5 & $42 \%$ & 7 & $58 \%$ & 7 & $58 \%$ & 5 & $42 \%$ \\
\hline
\end{tabular}

Berdasarkan table diatas maka terjadi peningkatan antara pre test dan pos test pada pertemuan I.Ketuntasan klasikal mengalami peningkatan,pada pre test hanya terdapat 3 anak yang sudah tuntas.tetapi pada postes bertambah menjadi 4 anak yang sudah tuntas dengan kriteria ketuntasan Minimal (KKM) mengalami peningkatan walaupun hanya 1 peserta didik.Pada pertemuan 2 saat pretest terdapat 5 peserta didik yang tuntas dan saat post tes bertambah menjadi 7 peserta didik.prosentase ketuntasan klasikal meningkat. Pada pertemuan 1 hanya sebesar 33\% meningkat menjadi 58\%

Setelah melakukan refleksi pada siklus 1,maka diputuskan untuk melanjutkan pembelajaran pada siklus II.Hal ini dilakukan karena nilai peserta didik belum memenuhi KKM.Hasil belajar peserta didik dapat dapat dilihat pada table berikut

Tabel 2. Hasil Peserta Didik Siklus II

\begin{tabular}{l|l|l|l|l}
\hline \multirow{2}{*}{ Siklus } & \multicolumn{2}{|c|}{ Pre test } & \multicolumn{2}{c}{ Pos test } \\
\cline { 2 - 5 } & Pesdik & Pesdik belum & Pesdik tuntas & Pesdik belum \\
\hline
\end{tabular}




\begin{tabular}{l|l|l|l|l|l|l|l|l}
\hline & \multicolumn{2}{|l|}{ tuntas } & \multicolumn{2}{l|}{ tuntas } & \multicolumn{2}{l}{ tuntas } \\
\cline { 2 - 9 } & Jml & $\%$ & Jml & $\%$ & Jml & $\%$ & Jml & $\%$ \\
\hline Pertemuan 1 & 4 & $33 \%$ & 8 & $67 \%$ & 6 & $50 \%$ & 6 & $50 \%$ \\
\hline Pertemuan 2 & 6 & $50 \%$ & 4 & $33 \%$ & 9 & $75 \%$ & 3 & $25 \%$ \\
\hline
\end{tabular}

Pada siklus II ketuntasan klasikal mengalami peningkatan pada pretest pertemuan ke 1 hanya terdapat 4 eserta didik yang tuntas bertambah menjadi 6 pada saat postes.Pada pertemuan 2,pada saat pre test terdapat 6 peserta didik yang tuntas bertambah pada saat postest menjadi 9 peserta didik. Prosentase klasikal meningkat dari yang semula $50 \%$ pada pertemuan 1 bertambah menjadi $75 \%$

Setelah melakukan refleksi pada siklus II maka diputuskan untuk melanjutkan pada siklus III.Hal ini dilakukan agar mengetahui sejauh mana penerapan pembelajaran Discovery Learninga tidak hanya meningkatkan tapi juga mempertahankan hasil belajar peserta didik.Pada siklus III materi yang di ajarkan tentang kalimat perintah pada video. Hasil belajar peserta didik dapat dilihat pada table berikut.

Tabel 3. Hasil Peserta Didik Siklus III

\begin{tabular}{|c|c|c|c|c|c|c|c|c|}
\hline \multirow{3}{*}{ Siklus } & \multicolumn{4}{|c|}{ Pre test } & \multicolumn{4}{|c|}{ Pos test } \\
\hline & \multicolumn{2}{|c|}{ Pesdik tuntas } & \multicolumn{2}{|c|}{$\begin{array}{l}\text { Pesdik belum } \\
\text { tuntas }\end{array}$} & \multicolumn{2}{|c|}{ Pesdik tuntas } & \multicolumn{2}{|c|}{$\begin{array}{l}\text { Pesdik belum } \\
\text { tuntas }\end{array}$} \\
\hline & $\mathrm{Jml}$ & $\%$ & $\mathrm{Jml}$ & $\%$ & Jml & $\%$ & $\mathrm{Jml}$ & $\%$ \\
\hline Pertemuan 1 & 6 & $50 \%$ & 6 & $50 \%$ & 9 & $75 \%$ & 3 & $25 \%$ \\
\hline Pertemuan 2 & 8 & $67 \%$ & 4 & $33 \%$ & 11 & $92 \%$ & 1 & $8 \%$ \\
\hline
\end{tabular}

Ketuntasan klasikal mengalami peningkatan,pada pretes pertemuan I peserta didik yang tuntas 6 anak yang tuntas bertambah menjadi 9 peserta didik.pada pertemuan 2,peserta didik yang tuntas saat pretes sebanyak 8 aanak bertambah saat post test menjadi 11 anak.Hal ini menunjukan terjadi peningkatan dari 75\% menjadi 92\%.ini menunjukan bahwa model Discovery Learning dapat meningkatkan hasil belajar peserta didik pada mupel Bahasa Indonesia kelas II di SDN Sindangheula 01. Hal ini sesuai dengan konsep atau teori yang di ungkapkan Penelitian ini sesuai dengan penelitian yang dilakukan oleh Nasrullah (2016) yang mengungkapkan bahwa penggunaan discovery learning dapat meningkatkan kompetensi kognitif siswa.

\section{SIMPULAN}

Penerapan model pemebelajaran Discovery Learning dapat meningkatkan hasil belajar peserta didik kelas II mupel bahsa Indonesia materi Kalimat Perintah .Peningkatan terjadi karena peserta didik mempunyai pemahaman dan pengetahuan yang dia bangun sendiri akan menghasilkan pengetahuan yang kuat dan dapat diingat selamanya karena begitu bermakna.

\section{DAFTAR PUSTAKA}

Arikunto,S., Suhardjono, Supardi. (2015). Penelitian Tindakan Kelas. Jakarta: PT Bumi Aksara.

Arief S. Sadiman. (2009). Media Pendidikan. Jakarta: PT Raja Grafindo Persada

Hosnan, M. (2014). Pendekatan Saintifik dan Kontekstualdalam Pembelajaran Abad 21. Bogor: Ghalia Indonesia.

Nasrullah, D. (2016). Pembelajaran Metode Discovery Learning Pada Mata pelaajaran Elektronika Dasar Siswa Kelas X Teknik Audio Video SMK Muhammadiyah 1 Bantul. Skripsi. Yogyakarta: Fakultas Teknik UNY.P.152 
SHEs: Conference Series 3 (3) (2020) 495- 499

Hamalik Oemar. (2001). Proses Belajar Mengajar. Bandung: Bumi Aksara.

Suherman, dkk. (2001). Keunggulan Metode Discovery ( http://herdy07.wordpress.com/2010/05/27/metode-pembelajaran-

Diakses) : penemuan/

Syah. (2004). Psikologi Pendidikan dengan Pendekatan Baru. Bandung: PT Remaja Rosdakary

Takdir. (2012). Pembelajaran Discovery Strategy dan Mental Vocational Skill. Jogjakarta : Diva Press. 